Research Article

\title{
Experimental Investigation of Unsaturated Silt-Sand Soil Permeability
}

\author{
Samad Nazari (D), ${ }^{1}$ Mahmoud Hassanlourad, ${ }^{2}$ Elham Chavoshi, ${ }^{3}$ and Ali Mirzaii ${ }^{4}$ \\ ${ }^{1}$ Department of Civil Engineering, Isfahan (Khorasgan) Branch, Islamic Azad University, Isfahan, Iran \\ ${ }^{2}$ Imam Khomeini International University, Qazvin, Iran \\ ${ }^{3}$ Department of Soil Science, College of Agriculture, Isfahan (Khorasgan) Branch, Islamic Azad University, Isfahan, Iran \\ ${ }^{4}$ University of Kashan, Kashan, Iran \\ Correspondence should be addressed to Samad Nazari; samad.nazari@gmail.com
}

Received 24 July 2017; Revised 15 October 2017; Accepted 18 October 2017; Published 23 January 2018

Academic Editor: Claudio Tamagnini

Copyright ( 2018 Samad Nazari et al. This is an open access article distributed under the Creative Commons Attribution License, which permits unrestricted use, distribution, and reproduction in any medium, provided the original work is properly cited.

\begin{abstract}
The permeability of unsaturated silt-sand soil is important in many geotechnical and geoenvironmental challenges. Therefore, an appropriate method to evaluate silt-sand soil permeability is important, particularly in Iran where it received little consideration. In this in vitro research, different amounts of fine silt were evaluated on behavior of an unsaturated silt-sand soil with different grain size distribution using a new modified triaxial apparatus. Permeability was measured against matric suction and volumetric water content, and the results are compared against experimental models. The results indicated that the behavior of unsaturated sandy soil permeability could be determined as a function of matric suction, soil void size, and percentage of fine aggregate. Furthermore, the results appeared to imply that an increase of fine contents reduced the permeability, specifically at higher values of suction. This trend for the reduction of soil permeability was related to the increase in the amount of fine contents.
\end{abstract}

\section{Introduction}

Many geotechnical and geoenvironmental problems include consideration of water flow through unsaturated soil. This requires an understanding on the coefficient of permeability within the soil, but features of unsaturated soil are subject to constant change. Changing features of unsaturated soil include slope, road and railway embankments, dams, and transport of pollutants. A wide range of changes in permeability of unsaturated soil is a major obstacle in analysis. There are numerous leaks that give rise to issues that might direct engineers to an assumption that it would be impossible to find a solution. However, experience shows that many questions relating to evaluation of leakage in unsaturated soil have already been answered.

The coefficient of permeability within the soil is a measure of the resistance of the soil against the flow of water [1]. In saturated soils, the soil permeability is a function of void spaces. However, in unsaturated soils, both water and air phases affect the flow of water within the soil, and the hydraulic conductivity of the soil is related to the amount of water content and soil void spaces [2]. Studies have shown that water only flows through soil gaps that have been continuously filled with water. So, permeability of unsaturated soil is related to two variables, special vertical stress and matric suction, that control the water content in unsaturated soil [3]. The matric suction has a significant influence on soil water content. The decreasing water content because of increased matric suction causes a considerable decrease in permeability of unsaturated soil. The soil permeability coefficient of unsaturated soil changes more than 10 times as the matric suction changes. Evaluations show that permeability of unsaturated soil has a close relation with the soil-water characteristic curve (SWCC) in drying and wetting processes $[4,5]$. In other words, unsaturated soil permeability has hysteresis behavior, as does the soil-water characteristic curve, which as the restructuring of the soil becomes minimal or reversible causes decreased hysteresis $[2,6,7]$. So, it seems necessary to indicate the permeability function in front of the matric suction.

Fredlund et al. [4] reported that the permeability of unsaturated soil is firstly defined from soil void size 
distribution, and indirectly the permeability coefficient of soil is defined by the soil-water characteristic curve. By assessing these aforementioned characteristics, it is not necessary to have an evaluation of the remaining water content in order to determine permeability of the unsaturated soil. The suggested permeability function is calculated from the integral relation between suction and water content. The suggested relations show good agreement with data obtained from the laboratory. Finally, the permeability coefficient function is gained against the matric suction by normalizing the permeability coefficient. Leong and Rahardjo [8-10] assessed 3 sets of permeability functions in unsaturated soil samples: experimental, microscopic, and statistical models. The theoretical history and operation of each set was evaluated against different laboratory data. They concluded that the statistical and experimental models had good compatibility with the laboratory results. Fredlund et al. [4] designed a flexible wall permeameter. Direct measurement was made on the unsaturated silty sand permeability coefficient using the combination of matric suction and special vertical stress. They concluded that the permeability coefficient in matric suctions lower than that in air-entry value suction is unchangeable. Also, the permeability coefficient in matric suctions above the air-entry value suction reduces with a high rate. Agus et al. [1] reported that Singapore has widespread distribution of unsaturated soil, so there is a need for permeability coefficients of soils, and due to difficulties in terms of cost and time, some functions have been presented to provide estimations of permeability of unsaturated soil. Results for estimations of soil permeability have shown good compatibility with results from laboratory tests.

Gallage et al. [7] used a newly developed parameter to measure unsaturated soil hydraulic conductivity by applying the steady flow method and direct measurement of matric suction. The device was prepared by two tensiometers that measured suction directly. For evaluating the new hydraulic conductivity method, two types of sand were measured in the drying and wetting procedures that demonstrated significant hysteresis behavior against the matric suction. But, hysteresis was not apparent when hydraulic conductivity was drawn against water. The results showed good coordination with functions of the estimated hydraulic conductivity. In their opinion, the new suggested relation just needed one extra parameter, and this was easily calibrated with the SWCC. To evaluate their studies, results of previous experiments were used and indicated good compatibility between the relation and the experiment results. In another study, a modified triaxial device was built to measure the permeability coefficient and the CD shear strength of 3 types of unsaturated soil in drying and wetting cycles on a sample [12]. The results showed good compatibility with the results reported in the literature. There have been many reports on permeability of unsaturated soil in the literature. Results have been determined by a variety of different methods and on different sets of samples. However, little is known about the effect of silty fine-grained soil on the permeability coefficient. The objectives of this study were to measure and compare the effects of different amounts of silt on the sand permeability coefficient. This was tested using a modified triaxial device.

\section{Approaches to Determine the Permeability of Unsaturated Soils}

In previous studies, the permeability of saturated soil $\left(K_{s}\right)$ was only evaluated in relation to the void ratio, while for unsaturated soils the permeability coefficient $\left(k_{w}\right)$ was related to both the void ratio $(e)$ and the water content $(w)$. As the void ratio $(e)$, degree of saturation $(s)$, and the water content $(\omega)$ are related to each other, $k_{w}$ can be presented as the following, which is a function of two of them:

$$
k_{w}=f(e, w) ; \quad k_{w}=f(s, e) ; \quad k_{w}=f(s, w) .
$$

If soil structure becomes incompressible, then the two parameters in (1) can be separated. This means that the saturated permeability coefficient $\left(K_{s}\right)$ determines the void ratio effect, and another function determines the water content in soil. Direct and indirect methods can be used to determine permeability in unsaturated soil [10].

Measuring permeability can be done either in a laboratory or in situ; however, local measurements are more easily available. Laboratory measurements are preferable because of accuracy and lower cost [13]. In other words, the indirect method of determining permeability of unsaturated soil is related to special characteristics such as SWCC. Direct measurement of permeability of unsaturated soil in a laboratory can be conducted using stable and unstable methods. The stable method (the fixed head or the fixed flow) used a fixed hydraulic head gradient afloat in the sample [2]. By creating water flow through the sample, matric suction and water content were fixed. However, according to Benson and Gribb [13], the stable method was more time consuming than the unstable method, but it had more accurate results using the Darcy law. Unstable methods such as variable head, penetration techniques, and immediate techniques are applicable in the laboratory and on location, but the methods have some differences. The main difference is in the flow procedure, hydraulic head measuring, and flow rate $[2,14]$.

The flow procedure can be a wetting procedure in which the water flows into a soil sample or it can be a drying procedure in which water flows out of a sample. When the variable head method is used to measure permeability, it is often difficult to maintain a stress state during tests [15]. Two permeameter have often been used to measure permeability of unsaturated soil; these include a rigid wall permeameter and a flexible wall permeameter [7, 16-19]. These have been used to measure permeability of unsaturated soil [15, 20-22].

The shape of the permeability function is near SWCC [4, 17]. Different research studies such as Richards [23], Brooks and Corey [24], Mualem [25], Kunze et al. [26], van Genuchten [27], and Leong and Rahardjo [10] have produced different functions for estimating permeability of unsaturated soil samples. Most functions have been based on the relation between SWCC and permeability, void size, and their distribution in soil. Permeability functions are able to estimate soil permeability very fast. However, some of these 
TABle 1: Empirical permeability functions and soil-water characteristic and permeability coefficient curve equations.

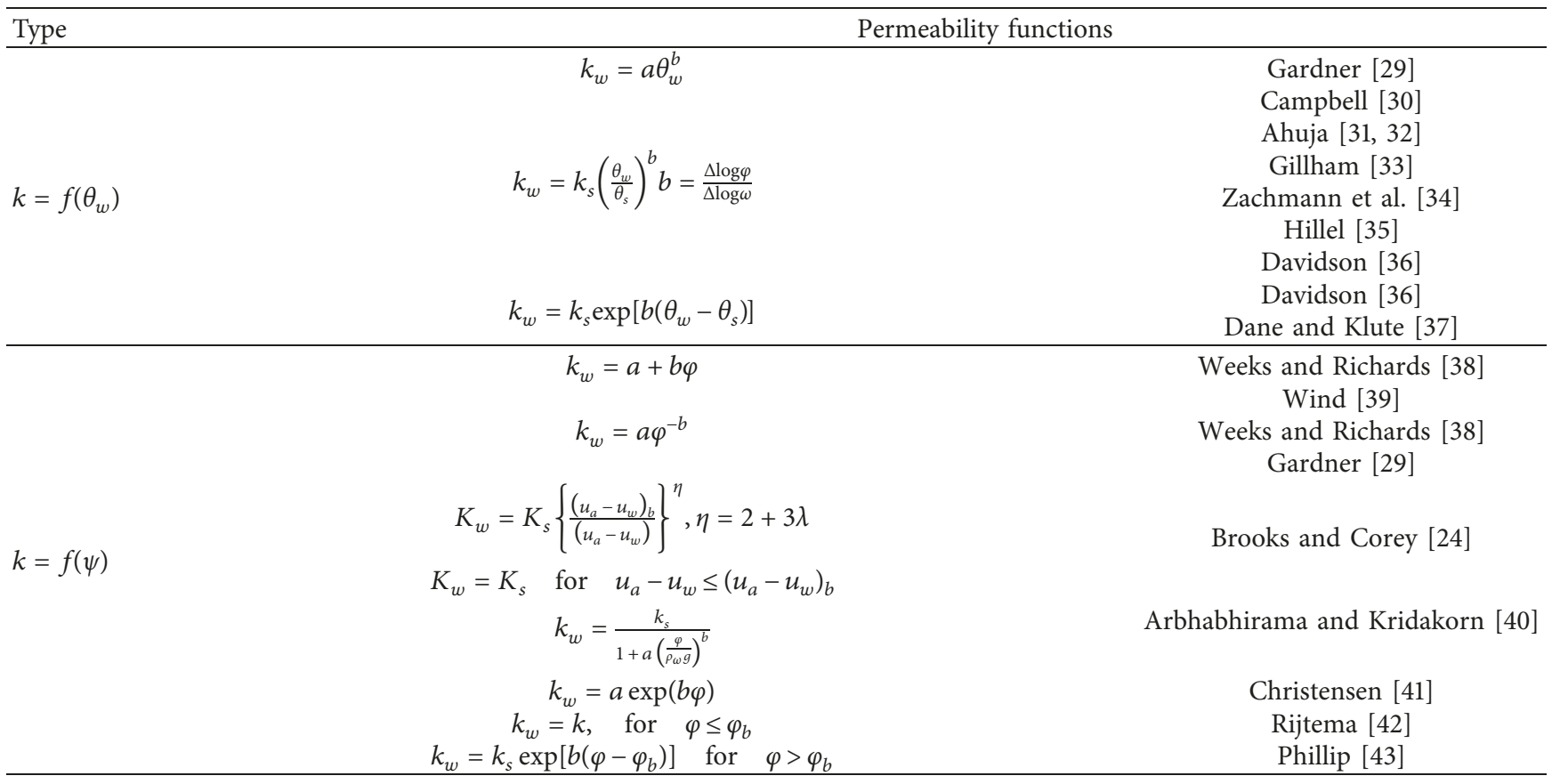

Note. $a$ and $b$ are constants; $k$ is coefficient of permeability where subscripts $w$ and $s$ denote unsaturated and saturated, respectively; $S$ is the effective degree of saturation; $\psi$ is the matric suction; $\theta_{w}$ is the volumetric water content.

functions ignore permeability in some types of unsaturated soil $[4,27,28]$. Hence, it is always recommended that although the permeability procedure is time consuming, it should be done completely for unsaturated soil [2].

There are three approaches to determine the permeability of unsaturated soil: (1) experimental equations, (2) microscopic models, and (3) statistical models. These three models are presented below.

\section{Experimental Equations}

The experimental equations of unsaturated soil permeability are gained based on laboratory data. The relation between permeability, matric suction $(\psi)$, and water content $\left(\theta_{w}\right)$ is as follows:

$$
k_{w}=f(\psi) ; \quad k_{w}=f\left(\theta_{w}\right)
$$

where $\psi$ is the matric suction and $\theta_{w}$ is the water content.

According to Leong and Rahardjo [8-10], the SWCC is similar to the suction-permeability curve (water content permeability). Some experimental permeability equations suggested from different researchers are shown in Table 1.

According to Table 1, for the $k_{w}=f(\psi)$ equation, different relations are suggested such as the linear function of Richards [23], the single power function from Weeks and Richards [28], and an exponential function from Philip [43]. And also for $k_{w}=f\left(\theta_{w}\right)$ power functions from Gardner [29], Campbell [30], and Gillham et al. [33], exponential functions from Davidson et al. [36] and Dane and Klute [37] were suggested. Comparison of this research on suggested functions for unsaturated soil permeability suggests the following relation:

$$
K_{r}=\Theta^{p}
$$

where $K_{r}$ is the relative permeability coefficient or the $K_{w}$ to $K_{s}$ ratio, $\Theta$ is the normalized volumetric water content $\operatorname{or}\left(\theta_{w}-\theta_{r}\right) /\left(\theta_{s}-\theta_{r}\right)$ in which $s$ and $r$ suffixes show saturated and remaining, respectively, and $P$ is constant.

The power $p$ in (3) covers an expanded domain of drying and wetting curves, and the fit curve in all states except for low volumetric waters seems to be fair. Leong and Rahardjo [8-10] in a critical review has assumed the $K_{r}=\Theta^{\mathrm{p}}$ relation as a function of $\psi$ and has modified [44] the relation and presented it as the following:

$$
K_{r}=\frac{1}{\left\{\ln \left(e+\left(\frac{\psi}{a}\right)^{b}\right)\right\}^{c d}},
$$

where $a, b, c$, and $d$ are fixed amounts and $a$ has a similar unit as $\psi$ (matric suction).

The mentioned relation shows good fitness with drying and wetting lab procedures. The writers of (4) concluded that $K_{w}$ can be determined directly from the soil-water characteristic curve. This method significantly decreases the errors of $K_{w}$ measuring, and finally the following equation is presented [8-10]:

$$
K_{r}=\frac{1}{\left\{\ln \left(e+\left(\frac{\psi}{A}\right)^{B}\right)\right\}^{C}},
$$

where $A, B$, and $C$ are fixed amounts.

3.1. Microscope Models. Firstly, microscopic models are presented based on a mechanistic view representing the 
fluid-filled pores as bundles of various sized capillary tubes $[8-10,24]$. The goal was to conclude a permeability function analysis. In a microscopic scale, the liquid flow is considered as a slow flow showing the general flow in the soil. When unsaturated soils are considered as a set of simple capillary tubes, the flow can be defined by using flow medium rate, hydraulic gradient, hydraulic radius, and permeability. The hydraulic radius measures efficiency of the flow channel. The flow rate along the channel depends on the cross-section area more than any other factor. The magnitude of the hydraulic radius shows high efficiency and results in higher flow volume [8-10].

According to assumptions in the mentioned paragraph, Brooks and Corey [24] recommended a microscopic model for the relative permeability ratio, which is defined as the unsaturated soil permeability coefficient to the saturated permeability coefficient.

$$
K_{r}=\frac{\left(S_{r}-S_{r}^{\mathrm{res}}\right)}{\left(1-S_{r}^{\mathrm{res}}\right)} \frac{\int_{0}^{S_{\mathrm{res}}} s^{-2} d S_{r}}{\int_{0}^{1} s^{-2} d S_{r}},
$$

where $\left(S_{r}-S_{r}^{\text {res }}\right) /\left(1-S_{r}^{\text {res }}\right)$ is the curvature factor due to the difference between the natural rate and the real rate of voids with the pressure real and natural gradient. $S_{r}$ and $S_{r}^{\text {res }}$ are the degree of saturation and the remaining degree of saturation, respectively. Also $\left(S_{r}-S_{r}^{\text {res }}\right) /\left(1-S_{r}^{\text {res }}\right)$ is named the effective degree of saturation $\left(S_{e}\right) \cdot \int_{0}^{S_{\text {res }}} s^{-2} d S_{r} / \int_{0}^{1} s^{-2} d S_{r}$ is the hydraulic radius which is gained from the integral of the SWCC. The effective permeability coefficient, like the suction powered function, could be presented as the following:

$$
K_{r}=S_{e}^{\delta}
$$

where $\delta$ is a constant number and can change due to the assumptions. Different researchers have recommended different numbers such as 3.5 by Averjanov [45], 2 by Yuster [46], 3 by Irmay [47], and 4 by Corey [48].

The main criticism of the microscopic models is that they ignore the effect of void size distribution $[24,49]$. Brooks and Corey [24] showed that $\delta$ for a soil with a uniform void distribution is equal to 3 and generally recommended the following relation: $\delta=2+3 \lambda / \lambda$, where $\lambda$ is the distribution index of void shape and is a positive number.

The experimental and microscopic models seem to be the same, but they each have a different theoretical base and excavation procedure. The experimental models are gained from the curve fitting on experimental data due to regression, but microscopic models are determined from liquid flow in a porous environment, which is based on fluid mechanics. Also, many microscopic models are related to soil-water retention behavior [8-10].

\section{Statistical Models}

Statistical models have been built based on statistical cooperation of void size changes on the permeability coefficient. The statistical perspective of void size distribution and the probability of the connections of pores are discussed in this part. Statistical models are known to be very accurate for calculating permeability of unsaturated soil [8-10]. In this model, the permeability coefficient function is gained using the SWCC. Three assumptions are required to extract the statistical model [8-10]:

(1) It is assumed that the soil is a system composed of interconnected collection and pore distribution is random, and the pore characteristics are gained by $r$ and $f(r)$ which is the same throughout the soil.

(2) The Hagen-Poiseuille equation is valid which is used to calculate the permeability of a unique pore channel, and general permeability is calculated according to integration of water-filled pores.

(3) Due to the Calvin capillary model, the SWCC used to gain the permeability equation is the representative of the soil pore distribution function.

According to technical literature, the statistical models can be presented as follows:

$$
\begin{gathered}
K_{r}\left(\theta_{w}\right)=\Phi^{x}\left[\frac{\left(\int_{0}^{\theta_{w}}\left(d \theta_{w} / S^{y}\right)\right)}{\left(\int_{0}^{\theta_{s}}\left(d \theta_{w} / S^{y}\right)\right)}\right]^{z} \\
K_{r}\left(\theta_{w}\right)=\Phi^{x}\left\{\frac{\left[\int_{0}^{\theta_{w}}\left(d\left(\theta_{w-\xi}\right) / S^{y}\right) d \xi\right]}{\left[\int_{0}^{\theta_{s}}\left(d\left(\theta_{w}-\xi\right) / S^{y}\right) d \xi\right]}\right\}^{Z},
\end{gathered}
$$

where $\Phi$ is the curvature factor and it is representative of the void size effect of pores on the permeability function, and it is shown that it improves the permeability coefficient function's estimation factor $\left(K_{r}\right)$ without a correction factor. The curvature facture is gained from normalizing $\left(\Phi=\left(\theta_{w}-\theta_{r}\right) /\left(\theta_{s}-\theta_{r}\right)\right)$ the water content, in which $\theta_{s}$ and $\theta_{r}$ are the water content in the saturated state and remaining state, respectively. In (8), $\xi$ is the integration artificial variable, and $x, y$, and $z$ are the constants of the model. For example, in the recommended model of Burdine [50], $x=2, y=2$, and $z=1$ for (7), while $x=$ $0.5, y=1$, and $z=2$ for Mualem [25]. For the Childs and Collis-George [49] model (CCG model), $x=0, y=2$, and $z=1$ in (8) were recommended, while for the modified CCG model, the numbers were $x=0, y=0$, and $z=2$ by using Agus et al. [15].

\section{Material Properties and Testing Methods}

A series of hydraulic conductivity tests were performed to examine the influence of silt fine content on the hydraulic conductivity of clean sand taken from the Firouzkouh area in the north of Iran [51].

A new modified suction-controlled double-walled triaxial apparatus was used for this purpose with the details illustrated in Figure 1. As shown, pore air and pore water pressures were applied throughout separate lines from both top and bottom of the specimens. Two one bar ceramic disks were installed at both top and bottom pedestals to 


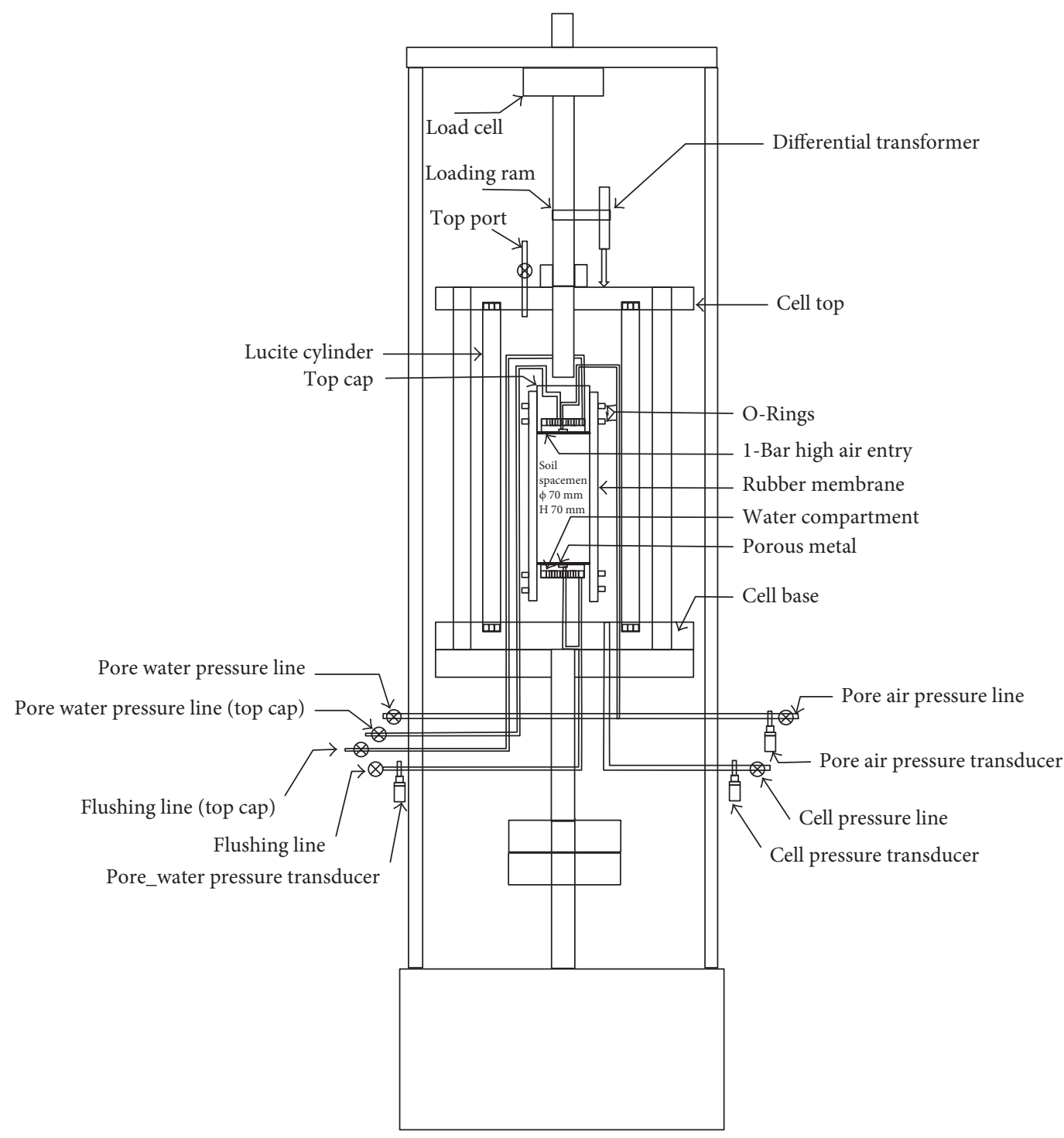

FIGURE 1: Schematic diagram of modified triaxial apparatus for permeability measurement.

control or measure the pore water pressure independently. The rate of inflow and outflow of the water was measured by means of two automatic pressure/volume change controllers. The Firouzkouh sand was mixed with the range of silt contents that were $0,10,20,30$, and $40 \%$ (i.e., FK0, FK10, FK20, FK30, and FK40, resp.). The basic properties of the five types of sand-silt mixtures considered in this study are summarized in Table 2. Accordingly, the variation maximum and minimum void ratio for the range of soil mixtures are illustrated in Figure 2. Also, Figure 3 represents the soil aggregation curve for the sand-silt mixtures considered.

Cylindrical triaxial samples with the same height and diameter $(7 \mathrm{~cm})$ and a relative density $\left(D_{r}\right)$, based on the ASTM D4254-16 code [52], were prepared in a specified dried special weight. The dry weight of each sample was calculated, and the samples were poured into a mold in some layers with the same weight. Table 3 shows the density properties of preparing the samples.
5.1. Determination of Water Permeability Coefficient. The permeability of an unsaturated soil can be calculated from the Darcy law [2, 49]:

$$
q_{t}=V A=K_{w} i A=K_{w} \frac{h}{L} A,
$$

where $q_{t}$ is the water flow rate in the cross section, $v$ is the flow speed, $A$ is the area, $K_{w}$ is the Darcy permeability coefficient (water permeability coefficient), $i$ is the hydraulic gradient which is equal to $\mathrm{h} / \mathrm{L}, h$ is the missed head, and $L$ is the height of soil sample.

The high air-entry ceramic plate permeability is considered in analyzing the results gained from the permeability test with the modified triaxial device. The soil permeability (or the water permeability) was determined in three layers: plate, soil, and plate [15]. The flow speed $(v)$ was the same in all three layers, while the general missed head $\left(h_{t}\right)$ is equal to the summary of the missed head in each layer (the upper plate, the soil sample, and the lower 
TABLE 2: Basic properties of the studied soil samples.

\begin{tabular}{|c|c|c|c|c|c|}
\hline \multirow{2}{*}{ Specification } & \multicolumn{5}{|c|}{ Sample } \\
\hline & FK0 & FK10 & FK20 & FK30 & FK40 \\
\hline Sand content (by dry weight) (\%) & 100 & 90 & 80 & 70 & 60 \\
\hline Silt content (by dry weight) (\%) & 0 & 10 & 20 & 30 & 40 \\
\hline Specific gravity, $G_{s}\left(\mathrm{gr} / \mathrm{cm}^{3}\right)$ & 2.658 & 2.663 & 2.684 & 2.671 & 2.652 \\
\hline Maximum dry density, $\gamma_{d, \max }\left(\mathrm{gr} / \mathrm{cm}^{3}\right)$ & 1.594 & 1.719 & 1.797 & 1.799 & 1.67 \\
\hline Minimum dry density, $\gamma_{d, \min }\left(\mathrm{gr} / \mathrm{cm}^{3}\right)$ & 1.385 & 1.423 & 1.424 & 1.402 & 1.356 \\
\hline $\begin{array}{l}\text { Saturated permeability coefficient } K_{s}(\mathrm{~m} / \mathrm{s}) \text {, } \\
\gamma_{d, \max }\left(\mathrm{gr} / \mathrm{cm}^{3}\right)=\text { constant }=1.4\end{array}$ & $8.41 e-2$ & $3.26 e-2$ & $9.42 e-3$ & $3.63 e-3$ & $3.13 e-4$ \\
\hline Plasticity index, PI & NP & NP & NP & NP & NP \\
\hline Maximum void ratio, $e_{\max }$ & 0.883 & 0.839 & 0.844 & 0.871 & 0.924 \\
\hline Minimum void ratio, $e_{\min }$ & 0.633 & 0.517 & 0.459 & 0.481 & 0.531 \\
\hline $\mathrm{D} 10(\mathrm{~mm})$ & 0.151 & 0.069 & 0.019 & 0.012 & 0.0069 \\
\hline $\mathrm{D} 30(\mathrm{~mm})$ & 0.194 & 0.174 & 0.156 & 0.077 & 0.032 \\
\hline $\mathrm{D} 50(\mathrm{~mm})$ & 0.25 & 0.233 & 0.214 & 0.191 & 0.164 \\
\hline $\mathrm{D} 60(\mathrm{~mm})$ & 0.285 & 0.269 & 0.253 & 0.229 & 0.203 \\
\hline $\mathrm{Cu}(\mathrm{D} 60 / \mathrm{D} 10)$ & 1.887 & 3.899 & 13.316 & 19.083 & 29.42 \\
\hline $\mathrm{Cc}\left((\mathrm{D} 30)^{2} /(\mathrm{D} 60 * \mathrm{D} 10)\right)$ & 0.875 & 1.631 & 5.063 & 2.158 & 0.731 \\
\hline Soil classification (USCS) & SP & SP-SM & SM & SM & SM \\
\hline
\end{tabular}

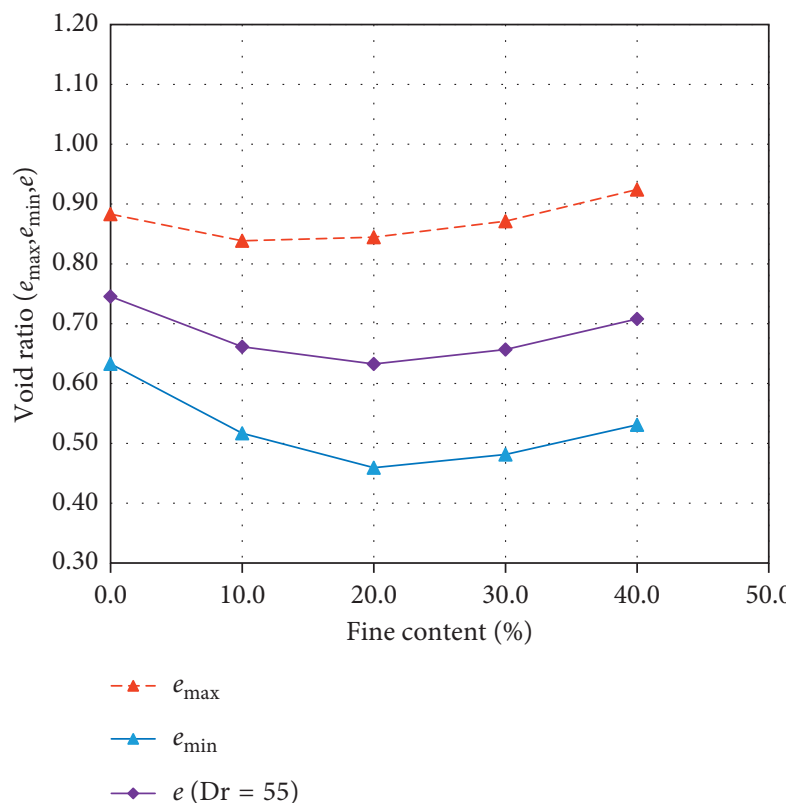

Figure 2: Void ratio curve for the prepared samples.

plate). The flow speed and the missed head have relations as follows:

$$
\begin{gathered}
v=v_{t}=v_{s}=v_{b}, \\
h_{T}=h_{t}+h_{s}+h_{b},
\end{gathered}
$$

where $v_{t}$ is the flow speed passing the upper ceramic plate, $v_{s}$ is the flow speed passing the soil sample, $v_{b}$ is the flow speed passing the lower ceramic plate, $h_{t}$ is the missed head along the upper ceramic plate, $h_{s}$ is the missed head along the soil

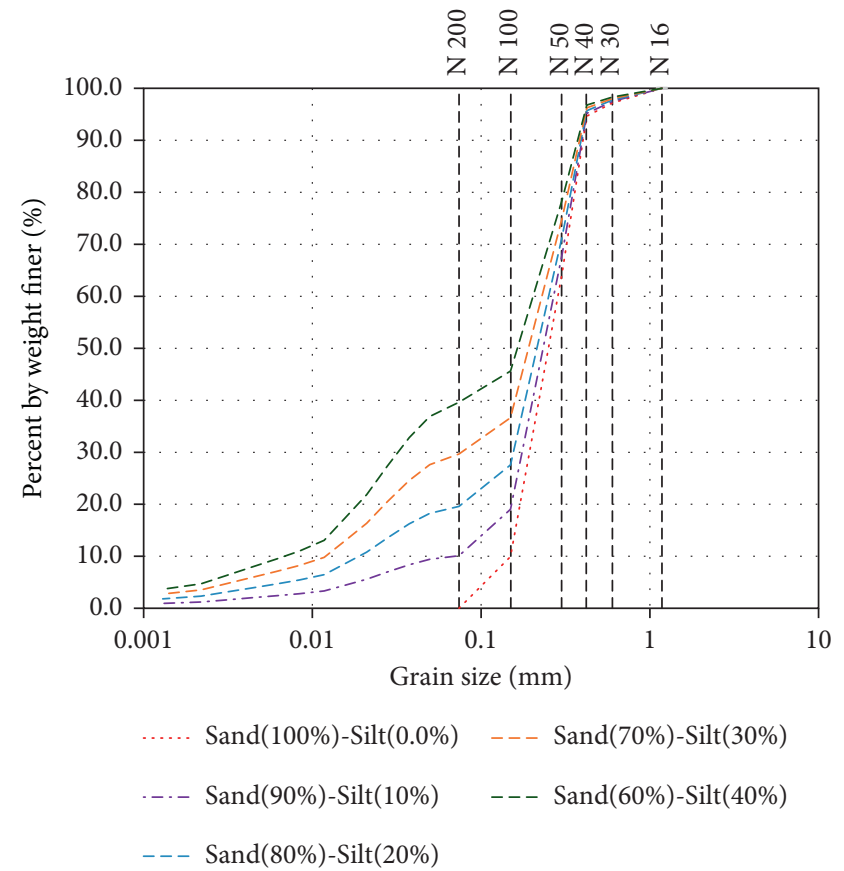

FIGURE 3: Grain size distribution of soil samples used in this study.

sample, and $h_{b}$ is the missed head along the lower ceramic plate.

By substituting relation (10) in relation (12), the following relation is gained:

$$
\frac{v_{T} l_{T}}{k_{T}}=\frac{v_{t} l_{t}}{k_{t}}+\frac{v_{s} l_{s}}{k_{w}}+\frac{v_{b} l_{b}}{k_{b}},
$$

where $K_{w}$ is the water permeability coefficient of the soil sample, $k_{T}$ is the permeability coefficient of the plate-soil-plate 
TABLE 3: Density properties of samples.

\begin{tabular}{lccccc}
\hline \multirow{2}{*}{ Specification } & \multicolumn{5}{c}{ Sample } \\
& FK0 & FK10 & FK20 & FK30 & FK40 \\
\hline Specific gravity, $G_{s}\left(\mathrm{gr} / \mathrm{cm}^{3}\right)$ & 2.658 & 2.663 & 2.684 & 2.671 & 2.652 \\
Maximum void ratio, $e_{\max }$ & 0.883 & 0.839 & 0.844 & 0.871 & 0.924 \\
Minimum void ratio, $e_{\min }$ & 0.633 & 0.517 & 0.459 & 0.481 & 0.531 \\
Dr $(\%)$ & 55 & 55 & 55 & 55 & 55 \\
$e(\mathrm{Dr}=55)$ & 0.77 & 0.694 & 0.671 & 0.696 & 0.747 \\
$\gamma_{d}\left(\mathrm{gr} / \mathrm{cm}^{3}\right)$ & 1.473 & 1.543 & 1.576 & 1.545 & 1.489 \\
\hline
\end{tabular}

TABLe 4: Porous ceramic plate properties (porous ceramic plate, $4 \mathrm{~mm}$ thickness, 1 bar high flow).

\begin{tabular}{lccc}
\hline Ceramic info & Thickness $(\mathrm{mm})$ & $K$ & Capacity (bar) \\
\hline High flow & 4 & $6.93 \mathrm{e}-7$ & 1 \\
\hline
\end{tabular}

system, $k_{t}$ is the water permeability coefficient of the upper plate, $k_{b}$ is the water permeability coefficient of the lower plate, $l_{s}$ is the soil sample length, $l_{t}$ is the upper ceramic plate thickness, $l_{b}$ is the lower ceramic plate thickness, and $l_{T}$ is the thickness of the plate-soil-plate system, that is, $l_{T}=l_{s}+l_{t}+l_{b}$.

When $v$ is the same in all layers, (13) can be rewritten as the following:

$$
K_{w}=\frac{l_{s}}{\left(l_{T} / k_{T}\right)-\left[\left(l_{t} / k_{t}\right)+\left(l_{b} / k_{b}\right)\right]} .
$$

So, the soil permeability coefficient can be calculated from (14). The permeability coefficient of the plate-soil-plate system $\left(K_{T}\right)$ can be calculated through permeability tests from the following equation:

$$
k_{T}=\frac{Q_{w}}{i A t},
$$

where $Q_{w}$ is the volume of water passing through the soil sample and $t$ is the time.

The properties of the porous plate used in this study are presented in Table 4.

In this study, the hydraulic conductivity tests were performed after drying and wetting of samples to a range of matric suctions between 1 and $60 \mathrm{kPa}$. A pore air pressure of $100 \mathrm{kPa}$ was applied to the specimens, and the pore water pressure was varied to reach the target matric suctions along drying and wetting paths. The hydraulic conductivity of samples was consequently measured within a steady state flow of water in the flow head of $30 \mathrm{kPa}$. Using a similar approach to Pavlakis [20] and Mirzaii \& Yasrobi [3], the average matric suction of specimens remained unchanged during the infiltration of water. This was experimentally achieved by $15 \mathrm{kPa}$ increment of sample bottom pore water pressure and $15 \mathrm{kPa}$ decrement of sample top pore water pressure, while the average pore water pressure was unchanged. The rates of inflow and outflow of water were reached to analogous constant values in a steady state condition within 30 to 50 hours.

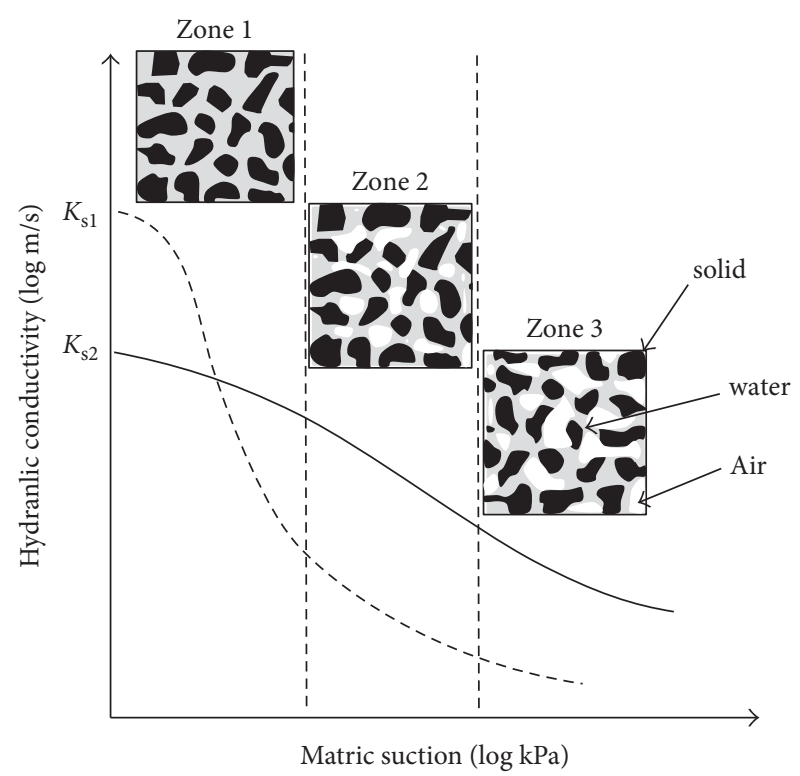

FIgURE 4: The general scheme of the matric hydraulic conductivitymatric suction curve for different types of soil.

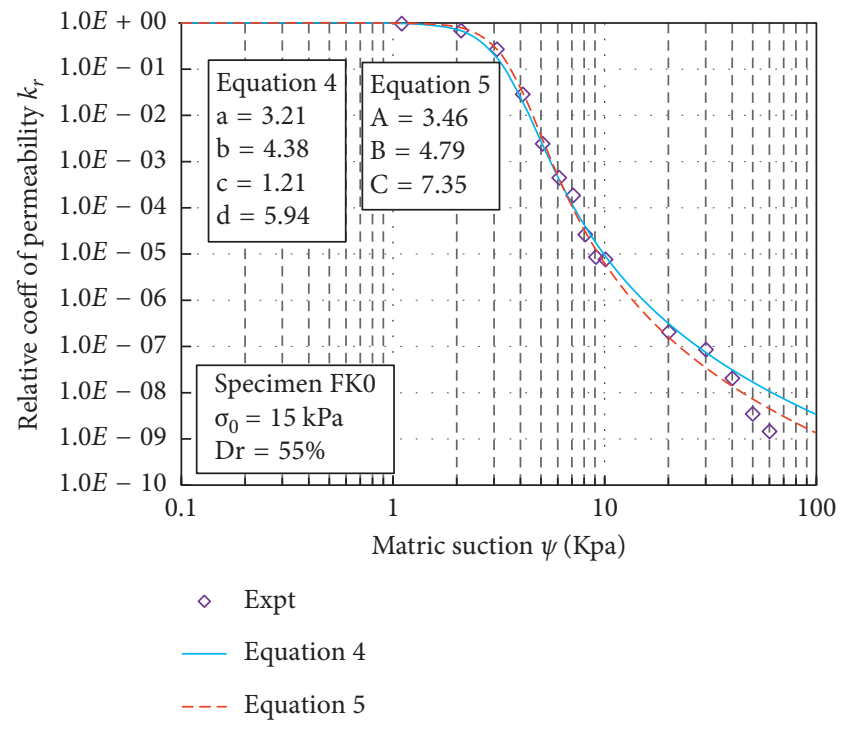

Figure 5: Permeability coefficient changes against matric suction for soil FK0.

\section{Results and Discussion}

In this part, the test results of this study are discussed based on experiments and the presented models [44]. The unsaturated soil permeability coefficient is presented according to (4) and (5). The results are presented in two parts: (1) permeability coefficient changes against the matric suction and (2) permeability coefficient changes against the volumetric water content.

6.1. Permeability Coefficient Changes against Matric Suction. The general scheme of the matric suction-permeability coefficient curve for different types of soil is shown in 


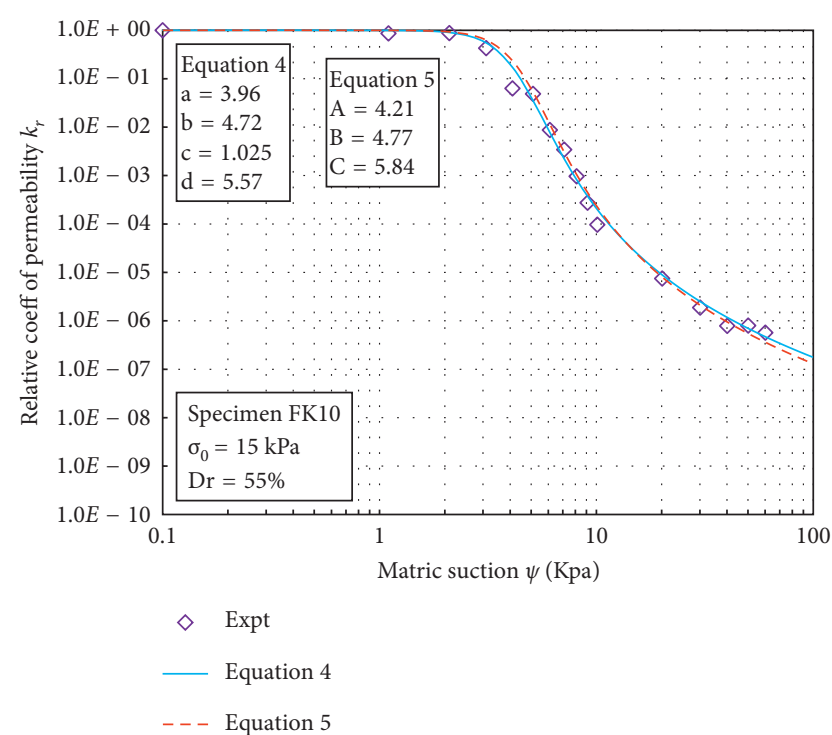

FIGURe 6: Permeability coefficient changes against matric suction for soil FK10.

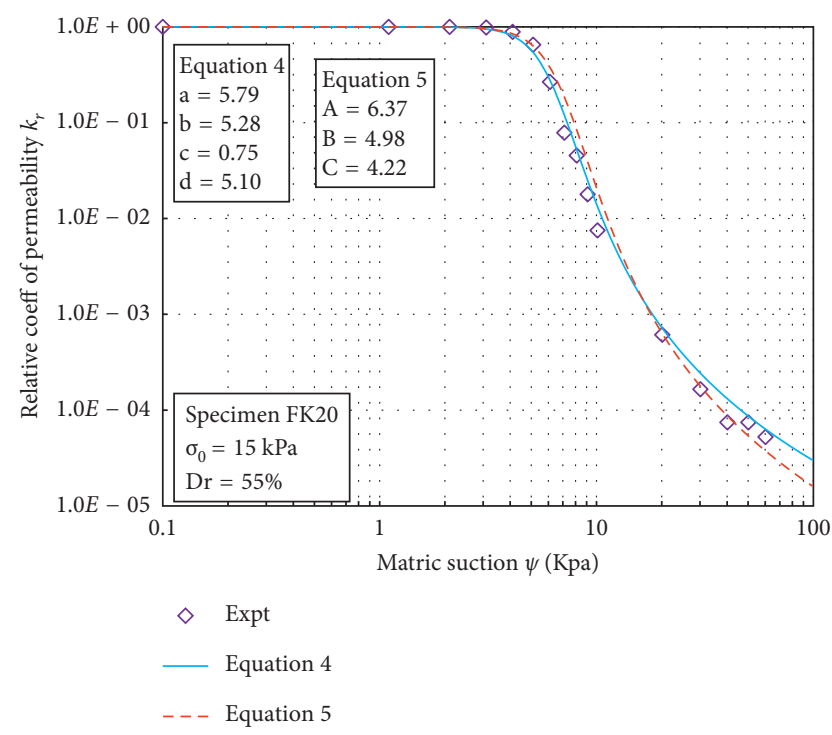

Figure 7: Permeability coefficient changes against matric suction for soil FK20.

Figure 4. This figure demonstrates that the general scheme was the same in different soil types, but the matric suction period and permeability coefficient evaluations were different according to soil type. According to continuity of the water and air phases in soil pores, the curve had 3 zones, and each zone had different soil behaviors. In the first zone, the voids were filled completely with water or distributed in the soil voids as discontinuous bubbles, and the soil behavior was just a function of water in the pores and demonstrated the same behavior as saturated soil. In the second zone, the soil pore was filled continuously with air and water, and the soil behavior was a function of the air and water inside pores. The third zone of the curve was similar to dry or nearly dry situations of the soil in which water was located in the thin

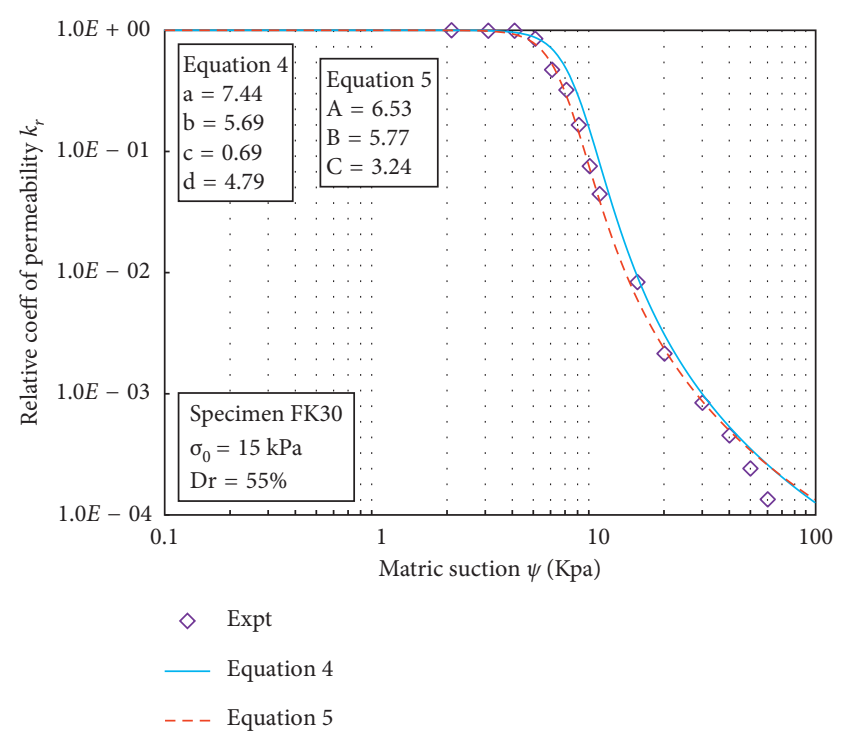

FIgURE 8: Permeability coefficient changes against matric suction for soil FK30.

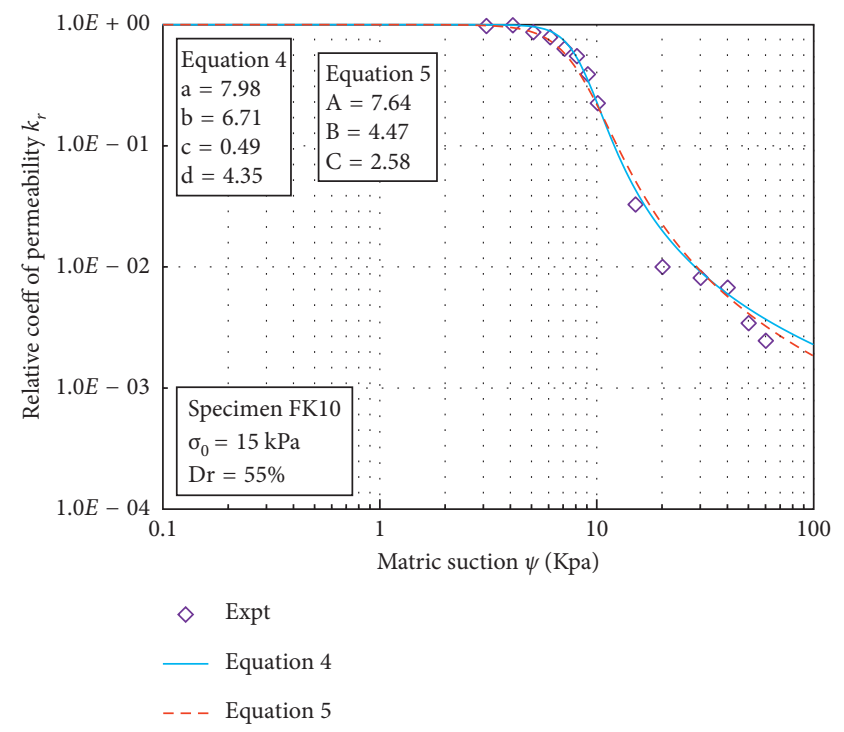

FIgURE 9: Permeability coefficient changes against matric suction for soil FK40.

layers between the soils. In this condition, most spaces in the voids were filled with air, and the capillary water distribution between layers is discontinuous.

In this study, the matric suction was applied between 0.1 and $60 \mathrm{kPa}$ depending on the soil type. Figures 5-9 show the soil permeability behavior of FK0, FK10, FK20, FK30, and FK40 against the matric suction, respectively.

The curves have been drawn from the data gained from permeability coefficients using relations and parameters of Leong and Rahardjo [8-10]. The amounts related to these parameters $(a, b, c, d$ and $A, B, C)$ are presented on the curves and shown separately in Tables 5 and 6 .

In low suction amounts between 0.1 and $5 \mathrm{kPa}$, depending on the soil type, the soil permeability behavior is 
TABLE 5: Parameters $a, b, c$, and $d$ for permeability function of soil specimens for (4).

\begin{tabular}{lcccc}
\hline Specimen & $a(\mathrm{kPa})$ & $b$ & $c$ & $d$ \\
\hline FK0 & 3.21 & 4.38 & 1.211 & 5.94 \\
FK10 & 3.96 & 4.72 & 1.025 & 5.57 \\
FK20 & 5.79 & 5.28 & 0.754 & 5.10 \\
FK30 & 7.44 & 5.69 & 0.696 & 4.79 \\
FK40 & 7.98 & 6.71 & 0.494 & 4.35 \\
\hline
\end{tabular}

TABle 6: Parameters $A, B$, and $C$ for permeability function of soil specimens for (5).

\begin{tabular}{lccc}
\hline Specimen & $A(\mathrm{kPa})$ & $B$ & $C$ \\
\hline FK0 & 3.46 & 4.79 & 7.35 \\
FK10 & 4.21 & 4.77 & 5.84 \\
FK20 & 6.37 & 4.98 & 4.22 \\
FK30 & 6.53 & 5.77 & 3.24 \\
FK40 & 7.64 & 4.47 & 2.58 \\
\hline
\end{tabular}

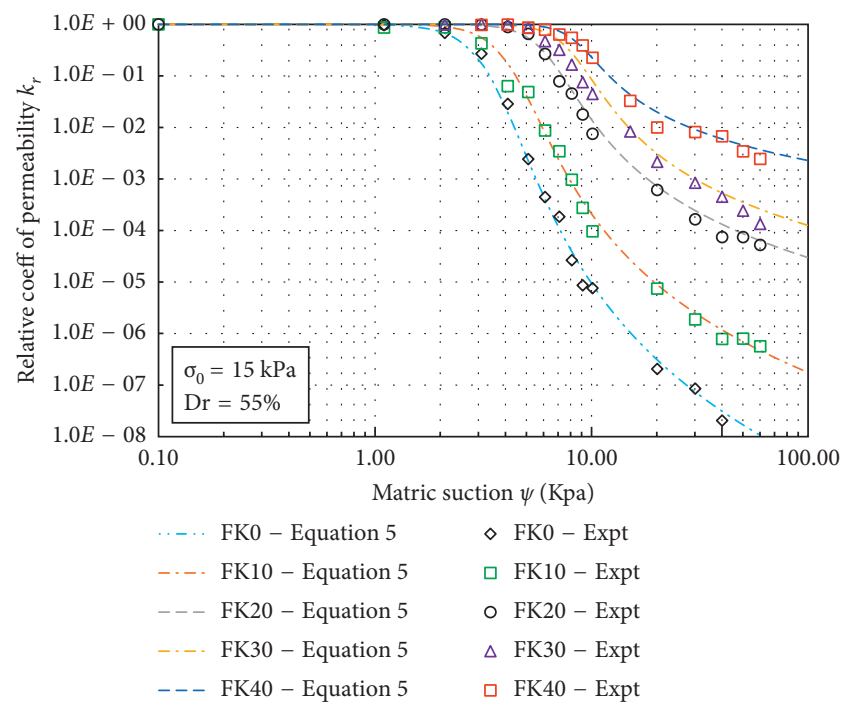

FIgURE 10: A comparison graph for permeability changes against matric suction for different soils.

different. Considerable changes happened by increasing the suction. As shown in Figures 5-9, by increasing the amount of silt, permeability was reduced in higher amounts of suction. The intensity of these changes for amounts of $20 \%$, $30 \%$, and $40 \%$ is shown in Figure 10 as a comparison.

Generally, the soil behavior in two relations 5 and 6 is the same. So, the previous graph is presented for (6). The results show that the permeability coefficient was the same for all soils at low level suction (lower than $1.5 \mathrm{kPa}$ ). But, the permeability coefficient showed difference as the matric suction increased. And as the suction increased and time passed, this difference became bigger and bigger. According to Figure 10, it can be seen that, at the same amount of suction more than $6 \mathrm{kPa}$, FK40 had the highest permeability coefficient, and FK0 had the lowest. It can be said that

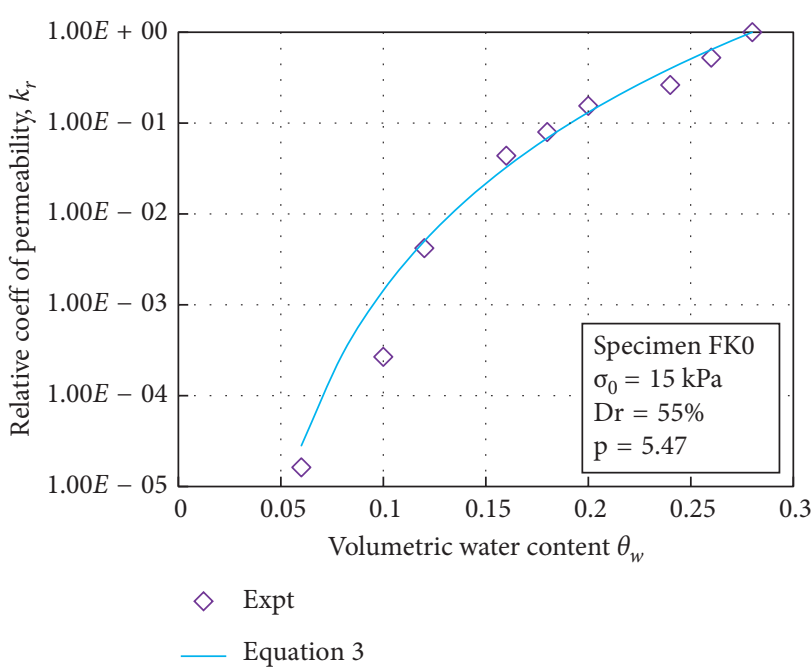

FIgURE 11: Permeability changes against volumetric water content for FK0 soils.

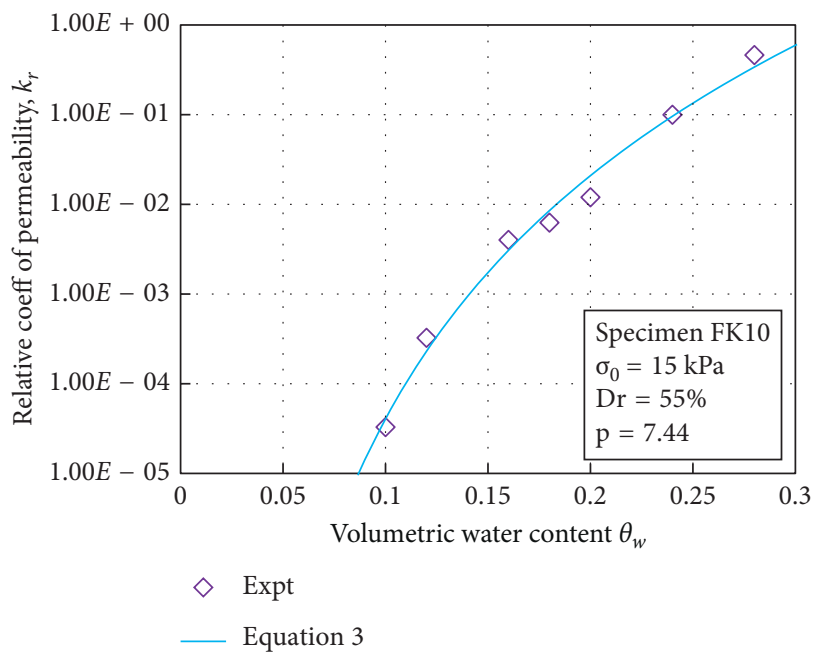

FIGURE 12: Permeability changes against volumetric water content for FK10 soils.

increasing the amount of silt caused a reduction in soil pore size and produced a denser and stable network for water to exit, which caused a reduction in general permeability of the soil. So, water needed more time to get out of the soil. Hence, the disconnection of waterways happened later, so the diagram was stretched higher. This behavior was seen in amounts of silt more than $10 \%$. In the second zone, the curve slope increased as the silt amount decreased. So, the FK40 had the least slope, and FK0 has the steepest slope. This behavior showed that, in samples with higher amounts of silt, water exited for a longer time.

6.2. Permeability Coefficient Changes against the Volumetric Water Amount. In this part, the permeability behavior was evaluated in different soil samples in this test against the volumetric water content. The behavior of these changes in different soils is shown in Figures 11-15. 


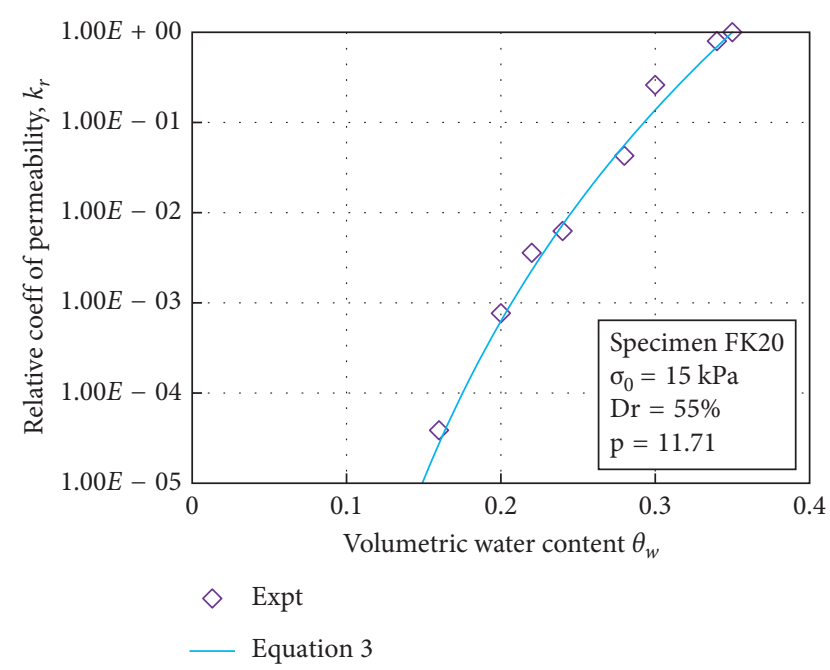

FIGURE 13: Permeability changes against volumetric water content for FK20 soils.

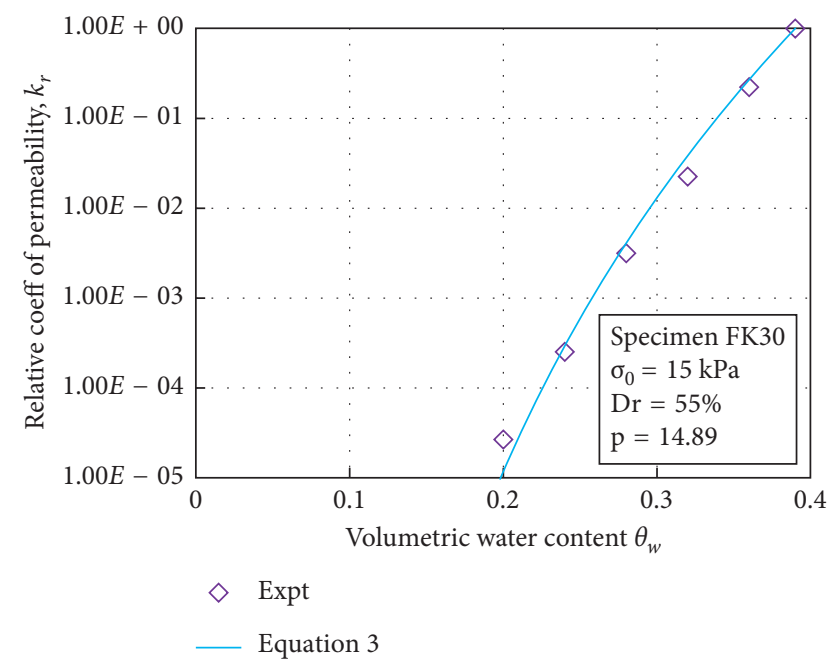

FIGURe 14: Permeability changes against volumetric water content for FK30 soils.

According to Figure 16, it is clear that, by increasing the volumetric water content through the sample, the permeability coefficient increased in all soils. The point is that the intensity of these changes increased as the silt amount increased. So, samples with $40 \%$ silt had a lower permeability coefficient, and with a decreasing amount of silt, the permeability coefficient increased. The pure sand sample FK0 had the highest permeability coefficient. This behavior was because of aggregation change in soil and the effect of pore size changes due to silt changes. As the soil pore size decreased, soil permeability also decreased.

\section{Conclusion}

This study considered in vitro evaluations and permeability behavior comparisons of unsaturated silty sand samples with different aggregations with relative density against matric

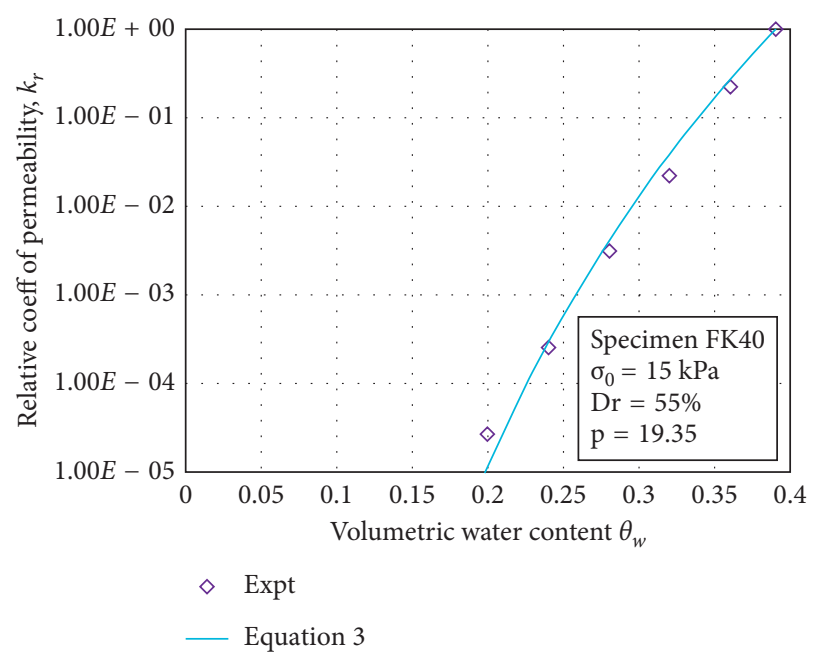

FIgURE 15: Permeability changes against volumetric water content for FK40 soils.

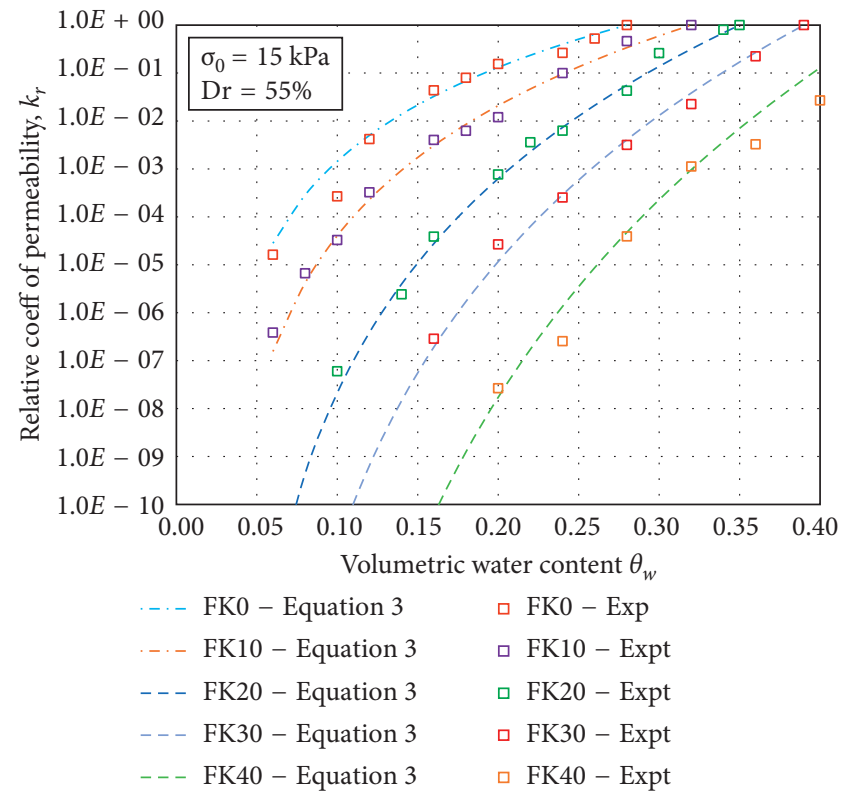

FIGURE 16: Comparison of figures of permeability changes against volumetric water content.

suction and volumetric water content using a modified triaxial device. The results were compared with different experimental models such as Leong and Rahardjo [8-10]. The results of this study are presented as follows:

(i) By increasing the amount of fine-grained aggregate, the permeability started to reduce at higher suction. This amount increased faster in soil samples with more silt.

(ii) An increase in fine grain caused a reduction of soil pore size and built a more stable and dense network for the water to exit. So, the water needed more time to exit the soil, and permeability decrease happened at a higher level of suction. 
(iii) The permeability against suction decreased as the fine grain increased. This shows that, at higher suction, the water exited the soil later, and this indicated that, in fine-grained soil, the permeability reduction rate was slower.

(iv) The permeability coefficient increased with different fine-grained percentages as the volumetric water increased, and the permeability coefficient decreased as the fine grains increased in a fixed amount of water. This behavior caused changes in aggregate percentage and pore size.

\section{Conflicts of Interest}

The authors declare that there are no conflicts of interest.

\section{References}

[1] R. D. Holtz and W. D. Kovacs, An Introduction to Geotechnical Engineering, Prentice-Hall, Upper Saddle River, NJ, USA, 1981.

[2] D. G. Fredlund and H. Rahardjo, Soil Mechanics for Unsaturated Soils, John Wiley \& Sons, New York, NY, USA, 1993.

[3] A. Mirzaii and S. S. Yasrobi, "Effect of net stress on hydraulic conductivity of unsaturated soils," Transport in Porous Media, vol. 95, no. 3, pp. 497-505, 2012.

[4] D. G. Fredlund, A. Xing, and S. Huang, "Predicting the permeability function for unsaturated soils using the soilwater characteristic curve," Canadian Geotechnical Journal, vol. 31, no. 4, pp. 533-546, 1994.

[5] A. Mirzaii, S. S. Yasrobi, and N. Khalili, "Experimental investigation of hydraulic conductivity in unsaturated compressible soils," in Proceedings of the 2nd European Conference on Unsaturated Soils, pp. 205-212, Napoli, Italy, June 2012.

[6] D. G. Fredlund, "Unsaturated soil mechanics in engineering practise," Journal of Geotechnical and Geoenvironmental Engineering, vol. 132, no. 3, pp. 286-321, 2006.

[7] C. Gallage, J. Kodikara, and T. Uchimura, "Laboratory measurement of hydraulic conductivity functions of two unsaturated sandy soils during drying and wetting processes," Soils and Foundations, vol. 53, no. 3, pp. 417-430, 2013.

[8] E. C. Leong and H. Rahardjo, "A review on soil-water characteristic curve equations," Journal of Geotechnical and Geoenvironmental Engineering, vol. 123, no. 12, pp. 1106-1117, $1997 b$.

[9] E. C. Leong and H. Rahardjo, "Discussion of Unsaturated hydraulic conductivity of two compacted barrier soils," Journal of Geotechnical Engineering, vol. 123, no. 12, pp. 1186-1188, 1997c.

[10] E. C. Leong and H. Rahardjo, "Permeability functions for unsaturated soils," Journal of Geotechnical and Geoenvironmental Engineering, vol. 123, no. 12, pp. 1118-1126, 1997a.

[11] S. S. Agus, E. C. Leong, and H. Rahardjo, "Estimating permeability functions of Singapore residual soils," Engineering Geology, vol. 78, no. 1-2, pp. 119-133, 2005.

[12] S. G. Goh, H. Rahardjo, and E. C. Leong, "Shear strength of unsaturated soils under multiple drying-wetting cycles," Journal of Geotechnical and Geoenvironmental Engineering, vol. 140, no. 2, p. 06013001, 2014.

[13] C. H. Benson and M. M. Gribb, "Measuring unsaturated hydraulic conductivity in the laboratory and field," in
Unsaturated Soil Engineering Practice, Geotechnical Special Publication No. 68, pp. 113-168, American Society of Civil Engineers, New York, NY, USA, 1997.

[14] H. Krisdani, H. Rahardjo, and E. C. Leong, "Use of instantaneous profile and statistical methods to determine permeability functions of unsaturated soils," Canadian Geotechnical Journal, vol. 46, no. 7, pp. 869-874, 2009.

[15] S. S. Agus, E. C. Leong, and H. Rahardjo, "A flexible wall permeameter for measurements of water and air coefficient of permeability of residual soil," Canadian Geotechnical Journal, vol. 40, no. 3, pp. 559-574, 2003.

[16] A. Klute, "Laboratory measurement of hydraulic conductivity of unsaturated soils," in Method of Soil Analysis, C. A. Black, D. D. Evans, J. L. White, L. E. Esminger, and F. E. Clark, Eds., vol. 1, pp. 253-261, Merican Society of Agronomy, Madison, WI, USA, 1965.

[17] J. K. M. Gan and D. G. Fredlund, “A new laboratory method for the measurement of unsaturated coefficient of permeability of soils," in Proceedings of the Asian Conference on Unsaturated Soils-From Theory to Practise, pp. 381-386, Singapore, May 2000.

[18] N. Lu, A. Wayllace, J. Carrera, W. J. Likos, L. David Suits, and T. C. Sheahan, "Constant flow method for concurrently measuring soil-water characteristic curve and hydraulic conductivity function," Geotechnical Testing Journal, vol. 29, no. 3, p. 12637, 2006.

[19] S. K. Vanapalli, V. K. Garga, and P. Brisson, "A modified permeameter for determination of unsaturated coefficient of permeability," Geotechnical and Geological Engineering, vol. 25, no. 2, pp. 191-202, 2007.

[20] C. H. Barden and G. Pavlakis, "Air and water permeability of compacted unsaturated cohesive soils," Journal of Soil Science, vol. 22, no. 3, pp. 302-318, 1971.

[21] S. Huang, D. G. Fredlund, and S. L. Barbour, "Measurement of the coefficient of permeability for a deformable unsaturated soil using a triaxial permeameter," Canadian Geotechnical Journal, vol. 35, no. 3, pp. 426-432, 1998.

[22] M. P. H. Moncada and T. M. P. Campos, "A new permeameter for the determination of the unsaturated coefficient of permeability," in Proceedings of the Fifth International Conference of Unsaturated Soil, UNSAT 2010, pp. 701-706, Barcelona, Spain, September 2010.

[23] L. A. Richards, "Capillary conducting of liquids through porous medium," Physics, vol. 1, no. 5, pp. 318-333, 1931.

[24] R. H. Brooks and A. T. Corey, Hydraulic Properties of Porous Media, Hydrology Paper, no. 3, Colorado State University, Fort Collins, CO, USA, 1964.

[25] Y. Mualem, "A new model for predicting the hydraulic conductivity of unsaturated porous media," Water Resources Research, vol. 12, no. 3, pp. 513-522, 1976.

[26] R. J. Kunze, G. Uehera, and K. Graham, "Factors important in the calculation of hydraulic conductivity," Soil Science Society of America Journal, vol. 32, no. 6, pp. 760-765, 1968.

[27] M. T. van Genuchten, "A closed form equation predicting the hydraulic conductivity of unsaturated soils," Soil Science Society of America Journal, vol. 44, no. 5, pp. 892-898, 1980.

[28] T. Chiu and C. D. Shack el ford, "Unsaturated hydraulic conductivity of compacted sand-kaolin mixtures," Journal of Geotechnical and Geoenvironmental Engineering, vol. 124, no. 2, pp. 160-170, 1998.

[29] W. R. Gardner, "Calculation of capillary conductivity from pressure plate outflow data," Soil Science Society of America Proceedings, vol. 20, no. 3, pp. 317-320, 1956. 
[30] G. S. Campbell, "A simple method for determining unsaturated conductivity from moisture retention data," Soil Science, vol. 117, no. 6, pp. 311-314, 1974.

[31] L. R. Ahuja, "A numerical and similarity analysis of infiltration into crusted soils," Water Resource Research, vol. 9, no. 4, pp. 987-994, 1973.

[32] L. R. Ahuja, "Unsaturated hydraulic conductivity from cumulative inflow data," Proceedings of Soil Science Society of America, vol. 36, pp. 695-699, 1974.

[33] R. W. Gillham, A. Klute, and D. F. Heermann, "Hydraulic properties of a porous medium: measurement and empirical representation," Soil Science Society of America Journal, vol. 40, no. 2, pp. 203-207, 1976.

[34] D. W. Zachmann, P. C. Ducthateau, and A. Klute, "The calibration of the Richards flow equation for a draining column by parameter identification," Journal of Soil Science Society of America, vol. 45, pp. 1012-1015, 1981.

[35] D. Hillel, Introduction to Soil Physics, Academic Press, New York, NY, USA, 1982

[36] J. M. Davidson, L. R. Stone, D. R. Nielsen, and M. E. Larue, "Field measurement and use of soil-water properties," Water Resources Research, vol. 5, no. 6, pp. 1312-1321, 1969.

[37] J. H. Dane and A. Klute, "Salt effects on the hydraulic properties of a swelling soil," Soil Science Society of America Journal, vol. 41, no. 6, pp. 1043-1049, 1977.

[38] L. V. Weeks and S. J. Richards, "Soil-water properties computed from transient flow data," Soil Science Society of America Journal, vol. 31, no. 6, pp. 721-725, 1967.

[39] G. P. Wind, "Field experiment concerning capillary rise of moisture in heavy clay soil," Netherlands Journal of Agricultural Science, vol. 3, pp. 60-69, 1955.

[40] A. Arbhabhirama and C. Kridakorn, "Steady downward flow to water table," Water Resource Research, vol. 4, no. 6, pp. 1249-1257, 1968.

[41] H. R. Christensen, Permeability-Capillary Potential Curves for Three Prairie Soils, Journal Paper No. J-1167, Project 504, Agricultural Experiment Station, Ames, IA, USA, pp. 381-90, 1943.

[42] P. E. Rijtema, "An analysis of actual evapotranspiration," Agricultural Research Report, Rep. 659, 1965.

[43] J. R. Philip, "Linearized unsteady multidimensional infiltration," Water Resources Research, vol. 22, no. 12, pp. 1717-1727, 1986.

[44] D. G. Fredlund and A. Xing, "Equations for the soil-water characteristic curve," Canadian Geotechnical Journal, vol. 31, no. 3, pp. 521-532, 1994.

[45] S. F. Averjanov, "About permeability of subsurface soils in case of incomplete saturation," English Collection, vol. 7, as quoted by $\mathrm{P}$.

[46] S. T. Yuster, "Theoretical consideration of multiphase flow in idealized capillary systems," in Proceedings of the Third World Petroleum Congress, vol. 2, p. 437445, Hague, Netherlands, 1951.

[47] S. Irmay, "On the hydraulic conductivity of unsaturated soils," Transactions, American Geophysical Union, vol. 35, no. 3, p. 463, 1954.

[48] A. T. Corey, "The interrelation between gas and oil relative permeabilities," Producer's Monthly, vol. 19, pp. 7-10, 1954.

[49] E. C. Childs and G. N. Collis-George, "The permeability of porous materials," Proceedings of the Royal Society A: Mathematical, Physical and Engineering Sciences, vol. 201, no. 1066 , pp. 392-405, 1950.

[50] N. T. Burdine, "Relative permeability calculation from pore size distribution data," Journal of Petroleum Technology, vol. 5, no. 3, pp. 71-78, 1953.
[51] S. Nazari, Evaluation of Liquefaction Potential Analysis of Partially Unsaturated Silty Sands, Ph.D. thesis, University of Isfahan (Khorasgan) Branch, Islamic Azad University, Isfahan, Iran, 2017.

[52] ASTM, "Standard Classification of Soils for Engineering Purposes (Unified Soil Classification System)," Annual Books of ASTM Standard D2487-93, vol. 4-8, pp. 217-227, ASTM, Philadelphia, PA, USA, Section 4, 1997. 


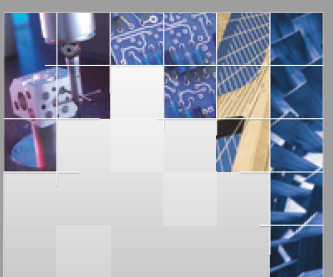

\section{Enfincering}
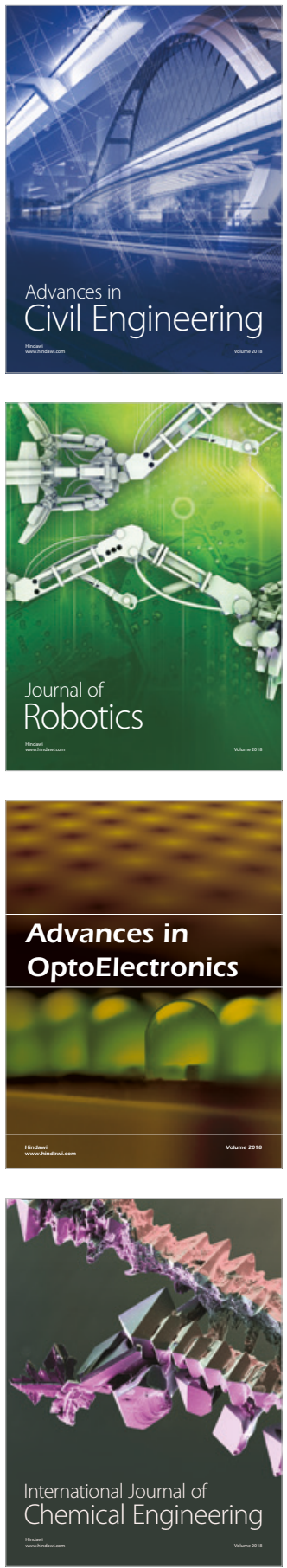

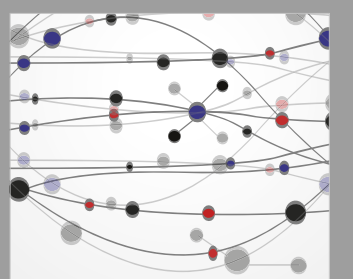

\section{Rotating \\ Machinery}

The Scientific World Journal

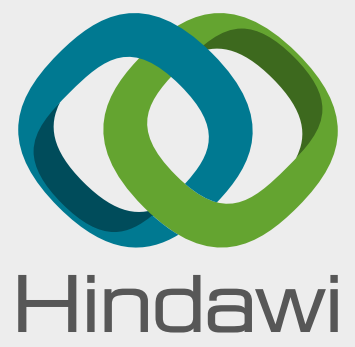

Submit your manuscripts at

www.hindawi.com
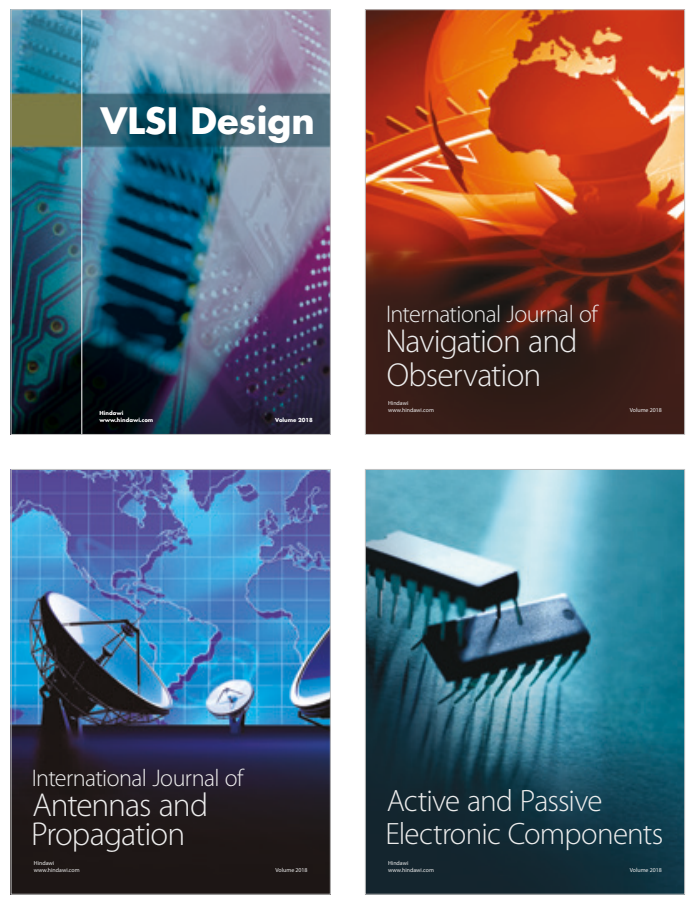
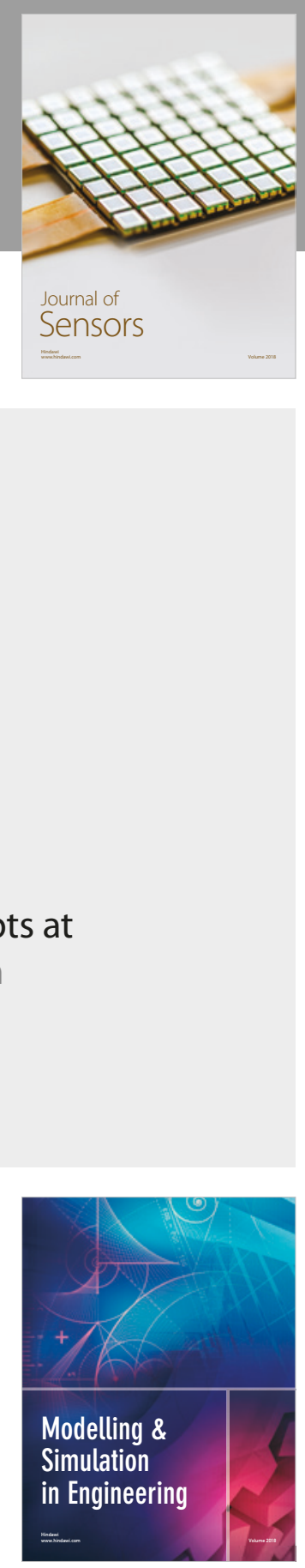

\section{Advances \\ Multimedia}
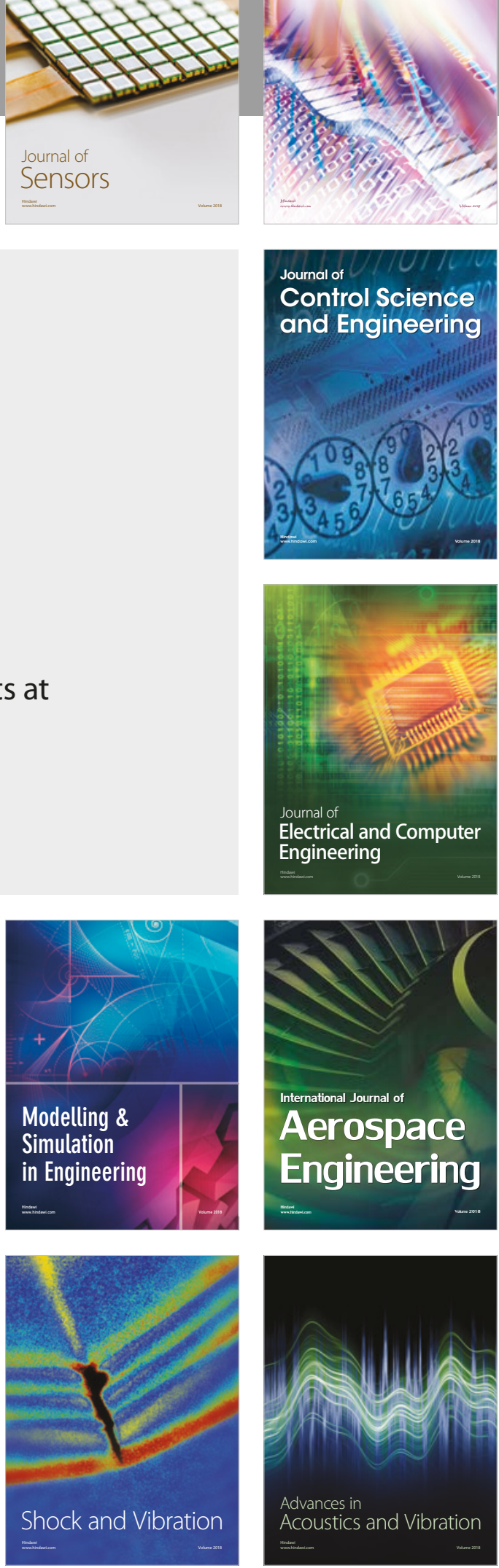